\title{
Healthcare Facility Identifier
}

National Cancer Institute

\section{Source}

National Cancer Institute. Healthcare Facility Identifier. NCI Thesaurus. Code C93846.

A unique symbol that establishes identity of the healthcare facility. 